NASA Technical Memorandum 100178

AIAA-87-2725

\title{
Initial Turbulence Effect on Jet Evolution With and Without Tonal Excitation
}

G. Raman

Sverdrup Technology, Inc.

Lewis Research Center

Cleveland, Ohio

and

K.B.M.Q. Zaman and E.J. Rice

Lewis Research Center

Cleveland, Ohio

Prepared for the

11th Aeroacoustics Conference

sponsored by the American Institute of Aeronautics and Astronautics Sunnyvale, California, October 19-21, 1987

\section{NASA}

(AASA-TM-100178) INITIAL TUBEULENCE BREECT

CN JET EVOLOTICN VITH AND FIIHCEI TCNAL

EXCITATICN (AASA) $17 \mathrm{p}$ AVII: NTIS HC

AC2/DF AO1

CSCL O1A

N87-27629 


\author{
G. Raman \\ Sverdrup Technology, Inc. \\ Lewis Research Center \\ Cleveland, Ohio 44135 \\ and \\ K.B.M.Q. Zaman, and E.J. Rice \\ National Aeronautics and Space Administration \\ Lewis Research Center \\ Cleveland, Ohio 44135
}

\section{Abstract}

The effect of initial turbulence level on the development of a jet and on the susceptibility of the jet to discrete tone excitation was experimentally investigated. Turbulence intensity was varied, over the range 0.15 to 5 percent, by using screens and grids placed upstream of an $8.6 \mathrm{~cm}$ diameter nozzie. Top-hat meañ velocity profiles with approximately identical initial boundary layer states were ensured in all cases; the turbulence spectra were broadband. It was found, contrary to earlier reports, that the natural jet decay remained essentially unchanged for varying initial turbulence.

For a fixed amplitude of the tonal excitation, increasing the initial turbulence damped out the growth of the instability wave; as a result, the excitability, assessed from the mean velocity decay on the axis, was found to diminish. However, the degree of damping in the amplification of the instability wave was only slight compared to the large increase in the initial turbulence. The jet with 5 percent turbulence could be measurably altered by excitation with a velocity perturbation amplitude as little as 0.25 percent of the jet velocity. The amplitude effect data indicate an upper bound of the extent to which a jet could be excited, and thus its plume shortened, by the plane wave, single frequency excitation.

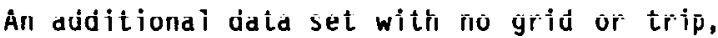
yielding a nominally laminar boundary layer. re-emphasizes the profound effect of initial boundary layer state on jet evolution as well as on its excitability. This jet decayed the fastest naturally, and consequently, it was the least excitable inspite of its turbulence being the least.

\section{Introduction}

The influence of an artificially imposed excitation on jet characteristics is fairly well documented. 1-6 In these studies, it was found that excitation could either enhance or suppress turbulence depending on the Strouhal number, amplitude and mode of excitation, as well as the Reynolds number and the initial boundary layer state. What has remained practically unknown is the effect of varying initial turbulence on the jet development, and consequently, on the susceptibility of the jet to discrete tone excitation.
One of the main differences between a jet engine exhaust and a laboratory model jet is in the initial core turbulence. Turbulence intensity in full-scale Turbojet (0lympus 593) and Turbofan (RB 211) engines have been reported to be 3 to 15 percent, while that in a laboratory jet is typically 0.5 percent or less. Thus, while considering the possibility of artificial control of "real life" jets, a question naturally arises: can such a jet be excited, and if so, to what extent?

Jet excitation experiments have been carried out taking into account the effect of various other factors like off-round nozzle shapes, 8 distorted velocity profiles, 9 heat flux, 10 ground effectsil and compressibility effects. 4 on the effect of initial turbulence, a set of experiments have been carried out by Soviet researchers, e.g. References 12 and 13 . Reference 13 reported a significantly faster jet decay with increasing turbulence. However, there are conflicting trends in the reported data. Although not discussed, a greater jet decay is indicated at 5 percent initial turbulence than at 10 percent initial turbulence. Thus, a careful recheck seemed to be in order. Also, the paper does not document or discuss the nature (spectra) of the turbulence, the exit velocity profile and the state of the boundary layer. On and Bushnel114 emphasized the necessity of such data while comparing their numerical results on a mixing layei spreau uinder variouis frea-stream conditions with another experiment by Vinogradov, et al. (see Ref. 14).

The objective of the present experiment was to gather a systematic set of data on the effect of initial core turbulence on the evolution of an axisymmetric jet and its response to acoustic excitation. In the preliminary stage, considerable effort was spent in fabricating and testing the grids that would produce various turbulence intensities but leave the top-hat exit profile unchanged. ${ }^{*}$ In the end, four cases were

* For reasons remaining unknown, a uniform square mesh grid with large blockage produced an axisymmetric but nonuniform mean velocity profile at the exit. For example, such a grid with 80 percent blockage yielded 15 percent higher mean velocity on the periphery than that on the axis. 
chosen in wich not only the profiles were top-hat but also the exit boundary layer thickness, shape factor and peak turbulence were approximately identical. A fifth case included is the original jet without any grid or trip having a "nominally laminar" boundary layer; the boundary layer was "nominally turbulent" for the other cases. These boundary layer states fall between the asymptotic "fully laminar" and "fully turbulent" states. 15 The effect of plane wave, tonal, acoustic excitation was then explored for the five cases as a function of excitation frequency and amplitude. The data cover a Mach number range of 0.05 to 0.44 , but most are for $M=0.3$ corresponding to a Reynolds number, $\operatorname{ReD}_{D}=6.1 \times 10^{5}$.

\section{Experimental Apparatus and Procedure}

The jet facility consisted of a $76 \mathrm{~cm}$ diameter plenum chamber supplied with pressurized air. The flow passed through three screens and two stages of contraction before exiting through the $8.8 \mathrm{~cm}$ diameter nozzle. A $20.3 \mathrm{~cm}$ butterfly valve bypassed by a $3.8 \mathrm{~cm}$ Annin plug valve, both operated remotely. were used to control the flow. A $41 \mathrm{~cm}$ dlameter section located between the two contracting sections housed the excitation system. This consisted of four acoustic drivers that were equally spaced about the circumference. Each driver was enclosed in a sealed can and vented to equalize pressure across the driver diaphragm.

Figure 1 is a schematic showing the geometry and location of the turbulence generating grids in the jet facility. The open circle represents the no grid, no trip case, the next one on the right the tripped case; the rest three are the $6 \times 6$ mesh screen case, and specially fabricated circular grid and radial grid cases. For brevity, these five cases will be referred to, herein after, according to the nominal turbulence intensities at the exit which were $0.15,0.15,0.5,3$, and 5 percent, respectively; the first case will be differentiated from the second with a qualifier, (L). For all the cases the blockage was less than 40 percent. The grids (or trip) were located $33 \mathrm{~cm}$ upstream of the nozzle exit where the diameter of the contracting section is $13.1 \mathrm{~cm}$; the nozzle ended with a sharp edge (unflanged) and had a $22 \mathrm{~cm}$ long cylindrical section prior to the exit.

A $0.64 \mathrm{~cm}$ (B\&K) microphone with a nose cone was used to obtain sound pressure levels and spectra. Measurements of mean and fluctuating velocity were made with single and crossed hot-wires together with constant temperature (DISA and TSI) anemometers. A computer controlled traversing mechanism was used for probe positioning.

\section{Results and Discussion}

Initial condition. The longitudinal mean velocity (U) and turbulence intensity ( $U^{\prime}$ ) profiles at the exit plane are shown in Fig. 2; the data have been normalized by the jet exit velocity, $U_{e}$. The data for the 0.15 percent case are essentialiy similar to the 0.15 percent $(L)$ case and thus not shown. The U-profiles are top-hat in shape in all cases. Note that the u'-profiles are flat in the core, except in the radial grid case which produced a radial variation with a minimum of about 3.8 percent at the center. An average over the core for the latter case is 5 percent. The turbulence measured in the boundary layer at positive $r$ is higher because the probe and its support mechanism entered the flow to reach this side; the flow impingment resulted in small probe vibrations which were sufficient to contaminate the data in the thin boundary layer. All subsequent measurements are on the axis or in the boundary layer on the negative $r$ side where only the probe and the stem entered the flow and thus vibration was minimal.

Figures $3(a)$ and (b) show velocity spectra measured at the exit center, all at $M=0.3$. Figure $3(a)$ shows $u^{\prime}$-spectra measured with a single hot-wire in 0 to $200 \mathrm{~Hz}$ range. The spectrum for the 0.15 percent case is essentially the same as that for the 0.15 percent (L) case and thus omitted for clarity. Figure $3(\mathrm{~b})$ shows $u^{\prime}$ - and $v^{\prime}$-spectra, measured with an X-wire, for the four cases as indicated. There are some isolated peaks, notably at $130 \mathrm{~Hz}$ (Fig. 3(a)), and at $1100 \mathrm{~Hz}$ and $2200 \mathrm{~Hz}$ for the 5 percent case (Fig. 3(b)). The origin of these remain unknown, but it was determined from streamwise spectral evolution that these were not amplified by the flow and thus were considered "harmless" in the present study. Figure 3(b) shows that for each case, the $u^{\prime}$ - and $v^{\prime}$-spectra are nearly identical indicating homogeneity in the Turbulence at the jet exit. The decay of turbulence within the nozzle downstream of the grids, shown in Fig. 4 , indicates that an "equilibrium" state has been reached in all cases by the nozzle exit.

The variation of the shape factor, the momentum thickness and the peak fluctuation level in the boundary layer, measured about $0.5 \mathrm{~mm}$ downstream of the nozzle lip, are shown in Figs. 5(a) to (c). These data demonstrate that the boundary layer characteristics for the cases $0.15,0.5,3$ and 5 percent are essentially the same in the $M$ range, 0.1 to 0.35 . As stated before the case 0.15 percent (L) exhibiting higher shape factor and fluctuation intensity is considered to have a "nominally laminar" boundary layer; all other cases are considered to have "nominally turbulent" boundary layers.

Figure 6(a) shows the variation of the fundamental rms velocity fluctuation at the excitation frequency ( $u^{\prime} \mathrm{fe}$ ) with the corresponding sound pressure level ( $\mathrm{L}_{e}$, dB $\operatorname{Re} 2 \times 10^{-5} \mathrm{~N} / \mathrm{m}^{2}$ ). These data were obtained by spectral analysis of the signals from a hot-wire and a microphone placed at the exit plane, separated by about 0.250 . Data for the 0.15 percent case are shown; corresponding data for the other four cases at high amplitudes are essentially the same. For the 3 and 5 percent cases, however, the slopes of these curves changed at low amplitudes due to the influence of the large turbulence. The nozzle impedance, $|\zeta|\left(=p^{\prime} f^{/ \rho c u^{\prime}} f \mathrm{fe}\right)$ is shown as a function of the normalized wavenumber $k R$ in Fig. 6(b). The solid curve represents the equation, $|\zeta|=4 k R / 3 \pi\left(1+5(k R)^{2}\left[1-0.6(k R)^{2}\right]\right)$. which was fitted to the 0.15 percent case data and is similar in form to the series expansion of the impedance of an unflanged nozzle. 16 Here $k$ is the wavenumber, $c$ the speed of sound, $R$ the nozzle radius, $\rho$ the density of air, and $p^{\prime} f e$ the fundamental rms pressure fluctuation which when expressed in $\mathrm{dB}$ is $L_{e}$. The data correlate quite well with this curve, and imply that a higher 
$\mathrm{L}_{e}$ is required at higher frequency to produce a constant u'fe, at least up to $1050 \mathrm{~Hz}$ covering the range of excitation frequencies which yield a reduction in the jet plume at $M=0.3$. Both $L_{e}$ and $u^{\prime} \mathrm{fe}$ have been used in the measurements as amplitude reference; Figs. $6(a)$ and (b) provide a cross reference between the two up to $1050 \mathrm{~Hz}$.

Excitability measurements. Figure 7 (a) shows the varlation of the mean velocity along the jet centerline $\left(U_{c}\right)$, without excitation, for the five cases, $U_{c}$ for the 0.15 percent $(L)$ case is seen to decay more rapidly compared to the tripped

( 0.15 percent) case; tripping extends the length of the developing region as also observed in e.g. Ref5. 17 and 18. The data show that the initial core turbulence, within the range covered, has insignificant effect on the jet evolution and decay. This is in sharp contrast to the data of Ref. 13, which show a large difference in the decay rates between jets with 0.5 and 5 percent initial turbulence. The reason for the difference remains unknown, as the initial conditions were not documented in Ref. 13. The following are possible contributing factors: (a) the initial boundary layer could have changed in the different cases, espectally as the Reynolds number was low (42000 to 70000$)$, (b) the turbulence could be concentrated in narrow frequency bands and oscillations assoclated with isolated peaks could have excited the jet.

The present data also contrast with the general inference of Ref. 14 which predicted as much as an order of magnitude change in a mixing layer spread rate depending on free-stream turbulence intensity and scale. However, the required turbulence to produce significant difference in the spread rate appears to be much nigher in the prediction of Ref. 14 than that covered in the present experiment.

The present data on jets with turbulent boundary layers agree we 11 with the tripped jet data of Ref. 1, and with the data of Ref. 13 for 0.5 percent turbulence. $U / U_{e}$ at $x / D=9$ is about 0.77 in all three cases. An initially laminar boundary layer results in a faster jet decay as clearly demonstrated by the present data. The vaiue $\hat{0} . i T$ hoids in the incompressidie in-range. At higher Mach numbers, the jet decay is slower; e.g., this value is 0.81 at $M=0.5,990.85$ at $M=0.6,4$ etc.

Figure $7(b)$ shows the variation of $U_{c}$ with and without excitation, at Strouhal number, St $\left(=f_{p} D / U_{e}\right)=0.47$ and $L_{e}=130 \mathrm{~dB}$. The effect of the excitation is perceptible in all cases. However, the effect clearly diminishes with increasing initial turbulence. The bottom figure is for the 0.15 percent (L) case showing a much lower effect even though the initial turbulence is sma 11: in this case, however, the natural jet decay is already large.

The turbulence intensity variations on the jet axis $\left(u^{\prime} c\right)$ are shown in Fig. 8(a); corresponding data with and without excitation for the five cases are shown in Fig. 8(b). (The turbulence measured near the exit was somewhat higher due to (DISA 55M25) linearizer noise: the curves have been faired in the $x / D$-range of 0 to 1 to the actual levels at the exit. The actual exit levels were determined in a separate experiment, excluding the linearizer with a carefully stabilized single hot-wire). A similar inference can be reached form these figures as arrived from Figs. $7(a)$ and (b).

The variation of the fundamental rms amplitude ( $\left.u^{\prime} f\right)$ corresponding to the five excitation cases of Fig. $8(b)$ are shown in Fig. 9. The growth and decay of the excited instability wave are represented by these curves. clearly, increasing the initial turbulence damps out the initial growth rate and the subsequent "saturation" amplitude. While $u^{\prime} f e / U_{e}$ is about 0.5 percent in all cases, the peak amplitude reached varied from about 5.3 percent at 5 percent turbulence to about 7 percent at 0.15 percent turbulence. Note that the 33 fold increase in the initial turbulence produced only about 25 percent damping in the instability wave growth. Note also that the location of "saturation" shifted downstream systematically with increasing turbulence. As before, the initially laminar case differs from the rest of the data trend. The maximum amplitude reached is lower than the initially tripped case; however the saturation iocations for the two cases are the same. The data in Figs. 7 to 9 consistently show that the jet with the most initial turbulence is affected the least by the excitation. Note, however, that the data are for a constant amplitude of the tone. One could conjecture that if the amplitude were suitably held constant relative to the broadband initial turbulence, the excitability should have been the same.

The mean velocity ratio with and without excitation measured at $x / D=9$ on the jet axis, denoted as $U_{\text {ex }} / U_{u x}$, is shown in Fig. 10 for varying $S t$. At about this measurement location the slope of the $U(x)$ variation is the largest (Fig. $7(a))$, and thus $U_{\text {ex }} / U_{u x}$ provides a sensitive measure of the effect of excitation. 4,10 For all the data in Fig. 10, Le was held constant at $130 \mathrm{~dB}$. Figure 10 (a) represents data at $M=0.3$ and Fig. $10(b)$ at $M=0.15$. (The data in (b) were taken at an earlier time when the 0.15 percent (tripped) case was not included). In both figures, the minimum $U_{e x} / U_{u x}$, representing the excitation condition producing the strongest effect, is found to occur at about $S t=0.5$. The same result was obtained by Ref. 10 for jets at higher Mach numbers as well as the heated jets. Note that at higher $S t$, there is a reverse effect of the excitation, prolonging the jet developing region. This is most pronounced for the initially laminar boundary layer case and

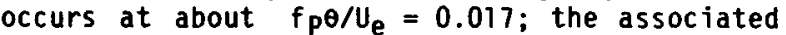
turbulence supression phenomenon was studied in Refs. 5 and 15 , and will not be pursued any further here.

Concentrating on the range of $S t$ where the effect is to enhance mixing, we found that the most effective St-range shifted if $u^{\prime} \mathrm{fe}_{\mathrm{e}} / \mathrm{U}_{\mathrm{e}}$ rather than $L_{e}$ was held constant. This is demonstrated in Fig. 11 where $U_{e x} / U_{u x}$ versus $S t$ is shown for the 0.15 percent (L) and 0.15 percent cases. The lowest point in these curves shifts to the range 0.6 to 0.7 when $u^{\prime} \mathrm{fe} / \mathrm{Ue}_{\mathrm{e}}$ is held constant. The shift could be reconciled from the fact that a higher $L_{e}$ is required at higher $f_{p}$ to obtain a constant 
u'fe (Fig. 6). Note that as the parameter $u^{\prime} f \mathrm{u}_{\mathrm{e}}$ is proportional to the fluctuating vorticity perturbation introduced into the shear layer, it is believed to be more pertinent in the excitation study. In passing we note that in a similar experiment on the effect of excitation on jet noise, in which $u^{\prime} \mathrm{fe} / \mathrm{U}_{\mathrm{e}}$ was kept constatnt, the maximum broadband noise amplification was also found to occur at $S t=0.7 .15$ Thus, the flow mechanism which leads to enhanced mixing and a reduced jet plume under the excitation seems also to be responsible for the "excess" noise radiation. It was conjectured in Ref. 15, based on the observed Strouhal number dependence and velocity spectra data, that this mechanism ought to be the induced pairing of the large scale coherent structures, Direct proof, e.g., through flow visualization, however, has yet to substantiate this conjecture.

The excitation amplitude effect at different St are shown in Fig. 12; (a) to (c) are for $M=$ 0.3 while (d) is for $M=0.15$. These data show the variation of $U_{e x} / U_{u x}$ over the available range of $\mathrm{L}_{e}$. They provide the threshold amplitude which is to be exceeded in order to produce a measurable effect. Note that for each $\mathrm{St}$, the threshold amplitude is the least for the 0.15 percent case and the highest for either the 0.15 percent $(L)$ or the 5 percent case. Note also that the threshold levels are much lower for the $M=0.15$ case; this can be reconciled by the fact that $L_{e}$ is not normalized by the jet dynamic head. The relative amplitude (e.g., $\left.u^{\prime} f_{f} / U_{e}\right)$ is essentially doubled, for a constant $L_{e}$, when the Mach number is halved.

One also notes from Fig. 12 that for the 5 percent case, a threshold of about $125 \mathrm{~dB}$ produces a measurable effect. Thus, invoking Fig. 6 , the amplitude $u^{\prime} \mathrm{fe}^{\prime} \mathrm{U}_{\mathrm{e}}$ of only 0.25 percent was sufficient to alter the jet with 5 percent initial turbulence. The threshold assessed from Fig. 12 can be subjective, but the above value agrees reasonably with those reported in both Refs. 2 and 4; the latter reported the threshold to be 0.08 percent of the dynamic head, the square-root of which should be proportional to $u^{\prime} \mathrm{fe}^{/ U_{e}}$. Finally, we also note that the curves in Fig. 12 tend to flatten out at high $L_{e}$ indicating an upper bound of the extent to which the jet could be excited, and thus its plume shortened, by the present method of excitation.

\section{Conclusions}

The natural jet evolution was found to remain unaffected for varying initial turbulence over the range covered in the present experiment. This is true for jets with initially turbulent boundary layers, and is apparent form both mean velocity and turbulence intensity variation on the jet axis.

The initial boundary layer state has a profound effect on the natural jet evolution and consequently on its excitability. The jet decay is faster in the initially laminar case than in the initially turbulent case. Tonal excitation increases the decay rate in both cases. However, for a given strouhal number and amplitude, the decay rate of the excited jet in either case is about the same. Thus, the excitability, i.e., the change relative to the corresponding unexcited state, is more pronounced in the initially turbulent boundary layer case.

For a given Strouhal number and amplitude of the tonal excitation, the instability wave growth damped out systematically with increasing initial turbulence. The location where the instability wave reached its peak amplitude also systematically shifted downsteam with increasing initial turbulence. However, the extent to which the peak amplitude decreased was small relative to the large increase in the initial turbulence. The jet with the maximum initial turbulence ( 5 percent) examined was very much susceptible to the excitation and could be altered measurably with amplitude $\left(u^{\prime} \mathrm{fe} / \mathrm{U}_{\mathrm{e}}\right)$ as little as 0.25 percent.

The effect of excitation Strouhal number is similar in jets with different initial turbulence; that is, the st-range where the effect is the maximum is the same in all cases. When the amplitude is held constant in terms of the SPL at the jet exit, the maximum effect is achieved at about $S t=0.5$. However, when the amplitude is held constant in terms of the velocity fluctuation, the most sensitive St-range shifts to about 0.6 to 0.7 . This is reconciled by the fact that the nozzle impedance increases with increasing St; thus, with higher St higher SPL is required to obtain a constant $U^{\prime} \mathrm{fe} / \mathrm{U}_{\mathrm{e}}$.

For a constant $S P L$, the jet is found to be much more excitable at $M=0.15$ than at $M=0.3$. This could again be viewed as an amplitude effect, as a constant SPL approximately corresponds to a constant $u^{\prime} f e$ and thus, the amplitude $u^{\prime} \mathrm{fe}^{/ U_{e}}$ is doubled when the Mach number is halved. It appears that the correct amplitude parameter for comparative study should be the velocity fluctuation, as this represents the relative vorticity perturbation introduced into the shear layer. The amplitude effect data also indicate an upper bound of the extent to which a jet could be excited by the single frequency excitation.

\section{Acknowledgment}

The authors like to thank Mr. M.D. Dahl for reviewing the manuscript.

\section{Reference}

1. Crow, S.C. and Champagne, F.H., "Orderly Structures in Jet Turbulence," Journal of Fluid Mechanics, Vol. 48, Part 3, Aug. 16, 1971, pp. 547-591.

2. Moore, C.J., "The Role of Shear-Layer Instability Waves in Jet Exhaust Noise," Journal of Fluid Mechanics, Vo 1. 80, Part 2, Apr. 25, 1977, pp. 321-367.

3. Bechert, D., and Pfizenmaier, E., "On the Amplification of Broad Band Jet Noise by a Pure Tone Excitation," Journal of Sound and Vibration, Vol. 43, No. 3, Dec. 8, 1975, pp. $581-587$.

4. Ahuja, K.K., Lepicovsky, 3., Tam, C.K.W., Morris, P.J. and Burrin, R.H., "Tone-Excited Jet: Theory and Experiments," NASA CR-3538, 1982. 
5. Zaman, K.B.M.Q. and Hussain, A.K.M.F., "Turbulence Suppression in Free Shear Flows by Controlled Excitation," Journal of Fluid Mechanics, Vol. 103, Feb. 1981, pp. 133-160.

6. Cohen, J. and Wygnanski, I., "The Evolution of Instabilities in the Axisymmetric Jet. Part 2. The Flow Resulting From the Interaction Between Two Waves," Journal of Fluid Mechanics, Vol. 176, Mar. 1987, pp. 221-235.

7. Smart, A.E. and Moore, C.J., "Aero-Engine Applications of Laser Anemometry." AIAA Journal, Vol. 14, No. 3, Mar. 1976, pp. 363-370.

8. Gutmark, E. and Schadow, K.C., "Flow Characteristics of Orifice and Tapered Jets," Physics of Fluids, 1987 (to appear).

9. Chan, Y.Y. and Templin, J.T., "Suppression of Spatial Waves by Distortion of Jet Velocity Profile," Physics of Fluids, Vol. 17, No. 11, Nov. 1974, pp. 2124-2125.

10. Ahuja, K.K., Lepicovsky, J., and Brown, W.H., "Some Unresolved Questions on Hot-Jet Mixing Control Through Artificial Excitation," AIAA Paper 86-1956, July 1986.

11. Lummus, J.R., "Criticality of Engine Exhaust Simulation on VSTOL Model-Measured Ground Effects," Journal of Aircraft, Vol. 18, No. 4, Apr. 1981, pp. 245-251.

12. Ginevskij, A.S. and Pochkina, K.A., "The Influence of Initial Stream Turbulence on the Characteristics of an Axisymmetric Immersed Jet," Inzhenerno-Fiszicheskii Zhurnal, Vol. 12, Jan. 1967, pp. 15-19.
13. Vlasov, E.V., Ginevskii, A.S. and Karavosov, R.K.. "Investigation of the Wave Structure of a Jet Entry-Zone Flow at Various Levels of Initial Turbulence," Fluid Mechanics -Soviet Research, Vol. 7, No. 3, May-June 1978, pp. 65-73.

14. Oh, Y.H. and Bushnell, D.M., "Influence of External Disturbances and Compressibility of Free Turbulent Mixing," Aerodynamic Analys is Requiring Advanced Computers, Part 1, NASA SP-347, 1975, pp. 341-376.

15. Zaman, K.B.M.Q., "Far-Field Noise of a Subsonic Jet Under Controlled Excitation," Journal of Fluid Mechanics, Vol. 152, Mar. 1985, pp. 83-111.

16. Morse, P. M. and Ingard, K.U., Theoretical Acoustics, McGraw-Hi11, New York, 1968.

17. Bradshaw, P., "The Effect of Initial Conditions on the Development of a Free Shear Layer," Journal of Fluid Mechanics, Vol. 26, Part 2, Oct. 1966, pp. 225-236.

18. Husain, 2.D. and Hussain, A.K.M.F., "Axisymmetric Mixing Layer: Influence of the Initial and Boundary Conditions," AIAA Journal, Vol. 17, No. 1, Jan. 1979, pp. 48-55.

19. Zaman, K.B.M.Q., "Flow Field and Near and Far Sound Field of a Subsonic Jet," Journal of Sound and Vibration, Vol. 106, No. 1, Apr. 8, 1986, pp. 1-16. 

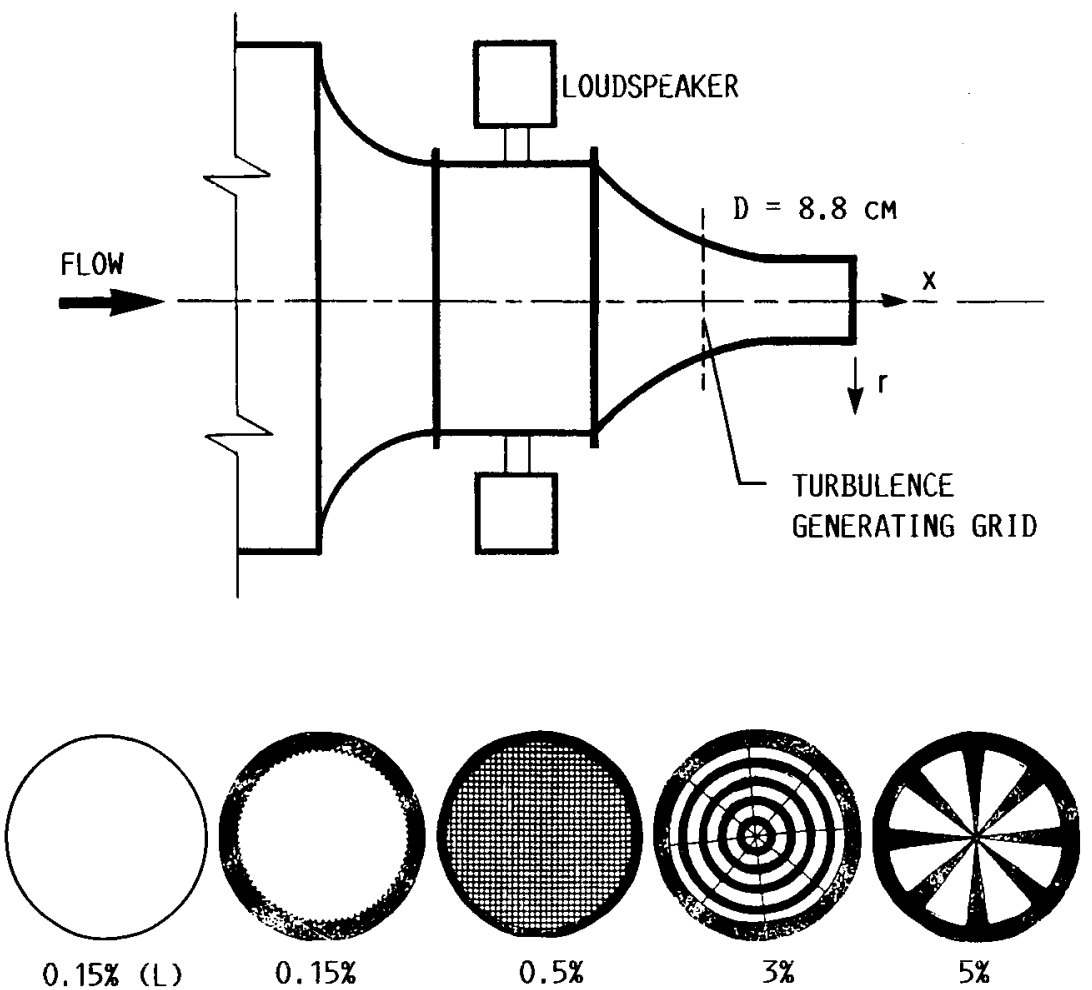

FIGURE 1. -SCHEMATIC OF JET FACILITY. THE FIVE GRID CASES ARE:

(1) NO GRID LAMINAR, (2) NO GRID TRIPPED, (3) $6 \times 6$ MESH SCREEN, (4) CIRCULAR GRID AND (5) RADIAL GRID. CORRESPONDING NOMINAL TURBULENCE INTENSITIES ARE INDICATED. 


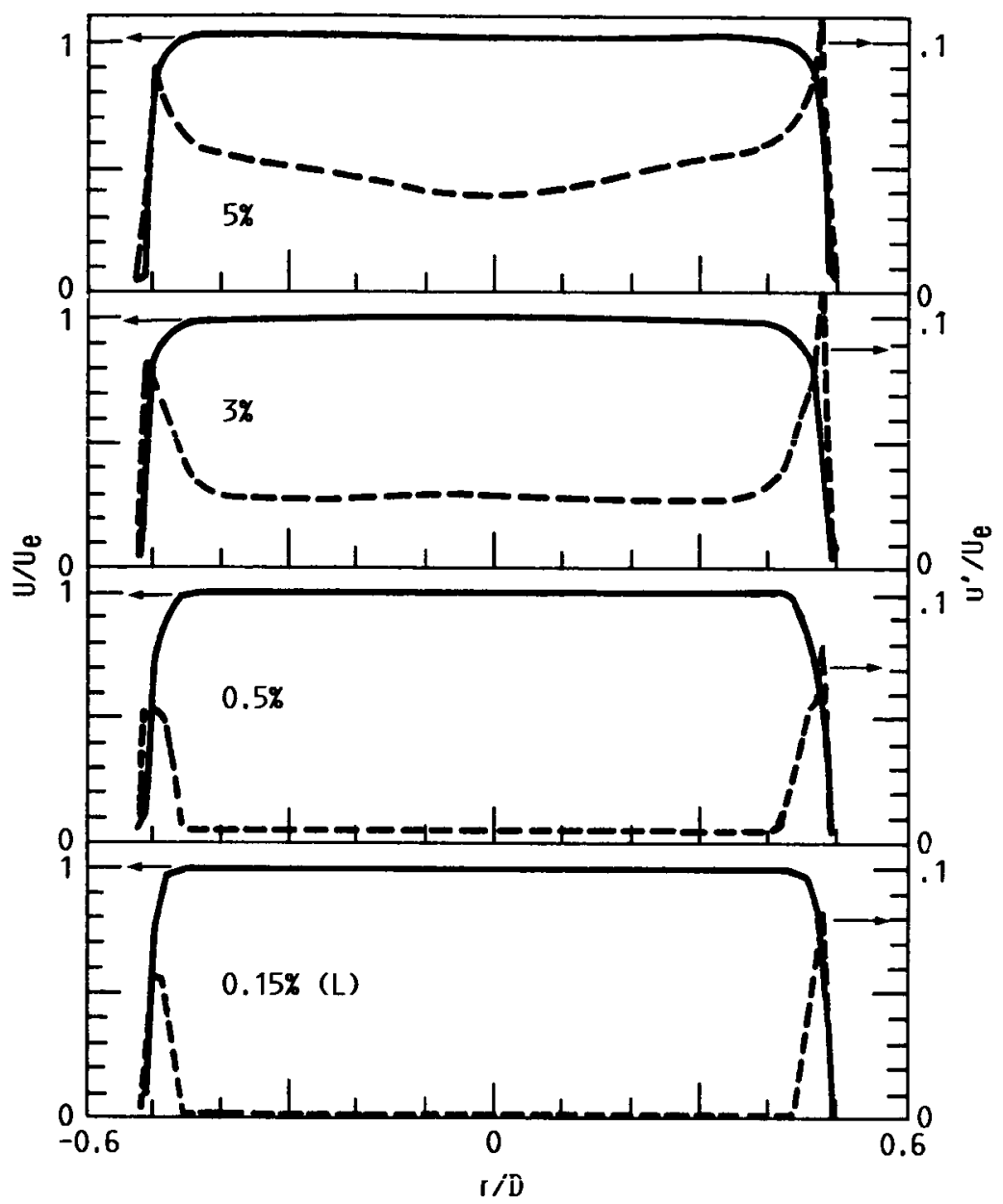

FIGURE 2. - RADIAL VARIATION OF MEAN VELOCITY (U, SOLID LINE) AND TURBULENCE INTENSITY ( $U^{\prime}$, DASHED LINE) AT THE JET EXIT, AT $M=0.3$. FOR THE FOUR CASES AS INDICATED. 

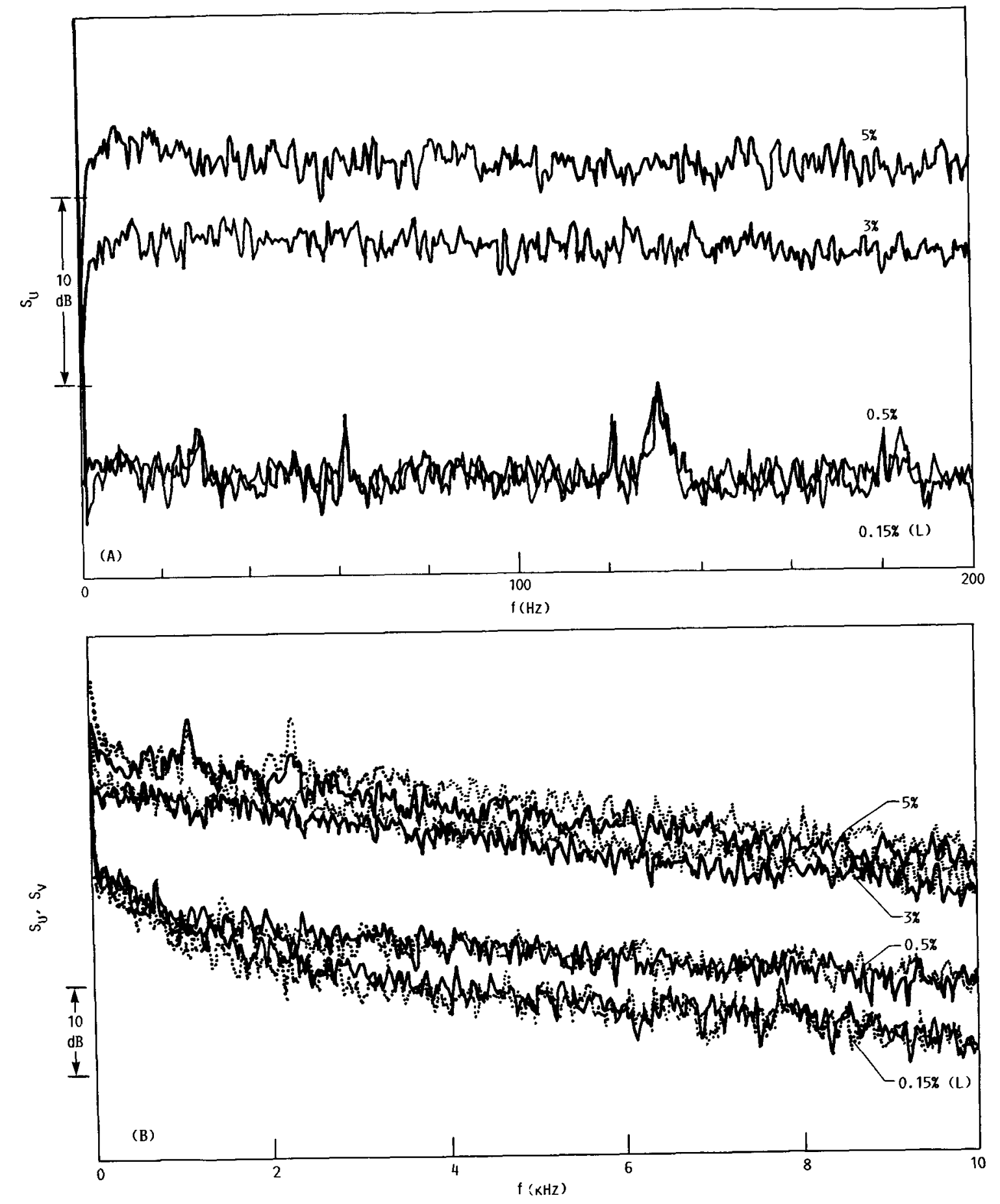

FIGURE 3. - (A) U-SPECTRA MEASURED AT JET EXIT CENTER AT $M=0.3$ FOR THE FOUR CASES AS INDICATED. THE ORDINATE SPANS -70 TO $-40 \mathrm{~dB}$; BANDWIDTH $=0.5 \mathrm{~Hz}$; JET VELOCITY CORRESPONDS TO $6 \mathrm{~V}$. (B) $u^{\prime}$ SPECTRA ( AND $v^{\prime}$-SPECTRA $(\ldots \ldots \ldots \ldots . . . .$.$) AT THE EXIT CENTER AT M=0.3:$ BANDWIDTH $=25 \mathrm{HZ}$. 


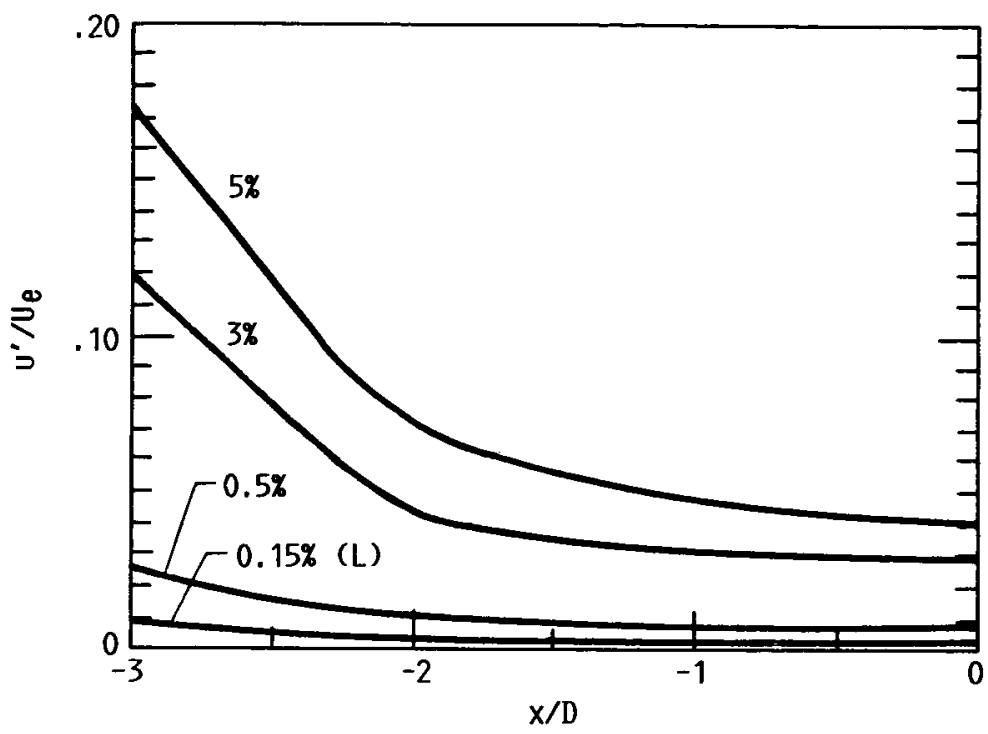

FIGURE 4. - TURBULENCE INTENSITY MEASURED INSIDE THE NOZZLE ON THE AXIS, AT $M=0.3$, FOR THE FOUR CASES.

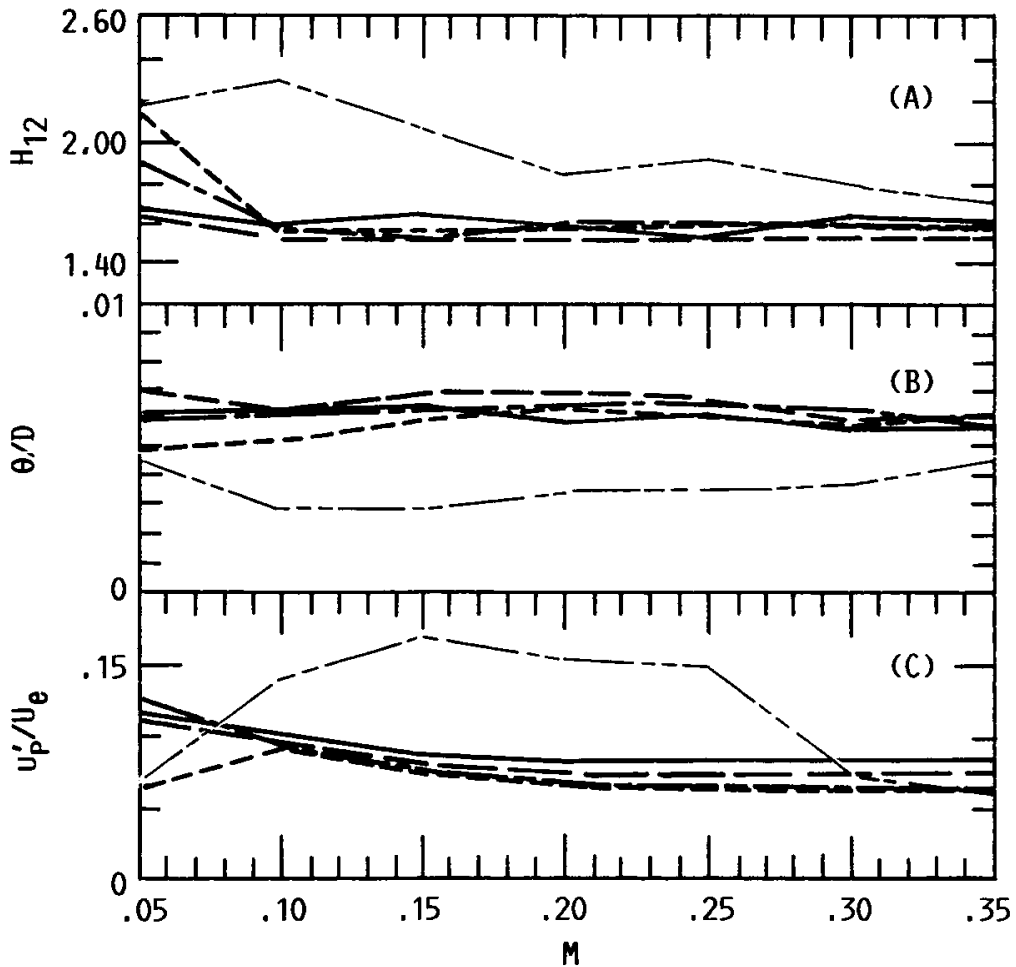

FIGURE 5. - BOUNDARY LAYER CHARACTERISTICS MEASURED 0.5 MM DOWNSTREAM OF JET EXIT, AT $M=0.3$.

(A) SHAPE FACTOR, (B) MOMENTUM THICKNESS, (C) PEAK FLUCTUATION INTENSITY, - $5 \%,--3 \%$,

$---0.5 \%,--0.15 \%,--0.15 \%(L)$. 

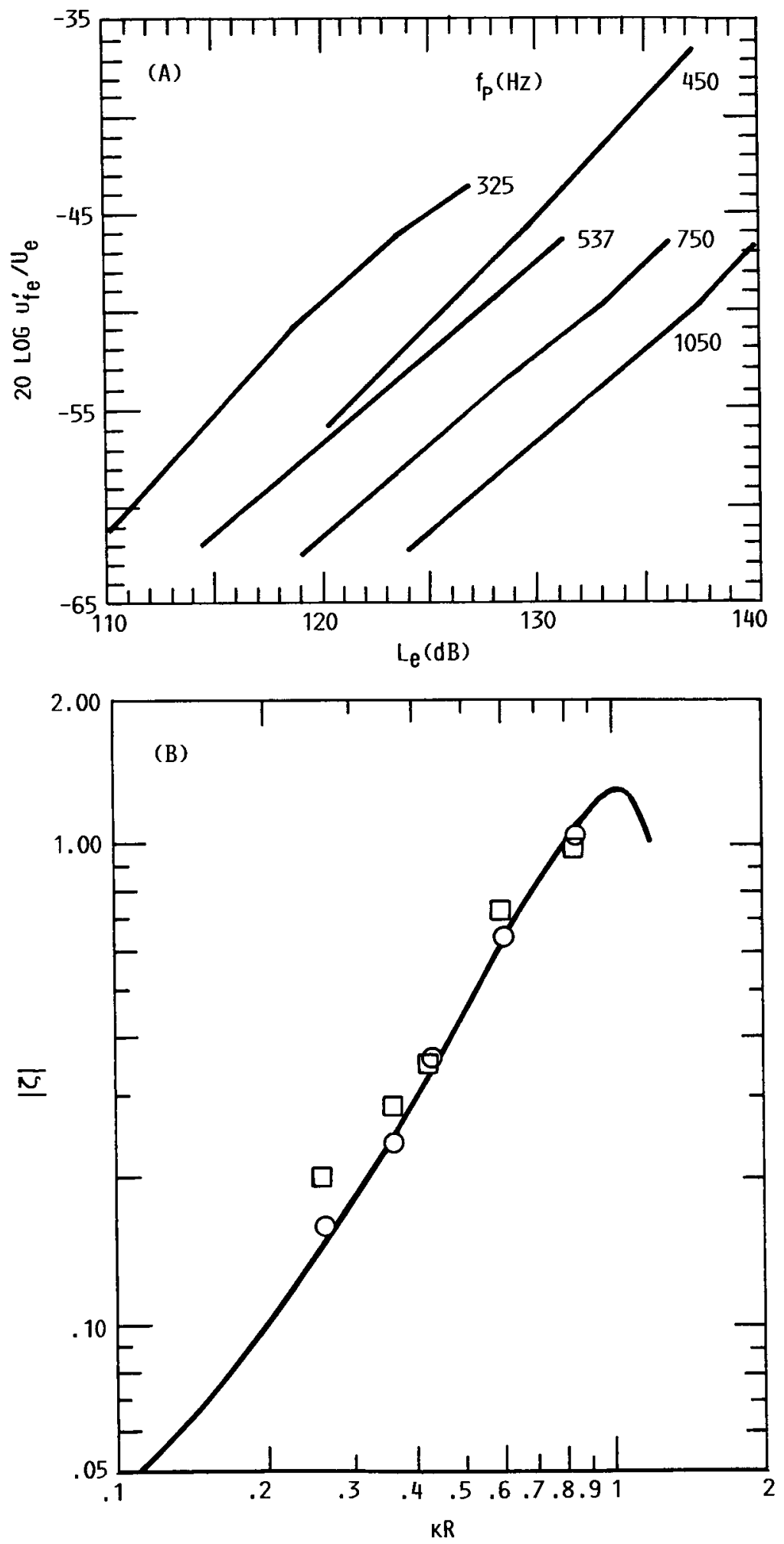

FIGURE 6(A). - VARIATION OF THE FUNDAMENTAL RMS VELOCITY FLUCTUATION $\left(u_{f e}^{\prime}\right)$ WITH THE CORRESPONDING SOUND PRESSURE LEVEL $\left(L_{e}\right)$, AT THE JET EXIT FOR THE 0.15\% CASE; $M=0.3$, (B) VARIATION OF NOZZLE IMPEDANCE $(|\zeta|)$ WITH WAVENUMBER (K); R IS NOZZLE RADIUS. SOLID LINE: EMPIRICAL CURVE: $O, 0.15 \%$ CASE: $\square, 5 \%$ CASE. 


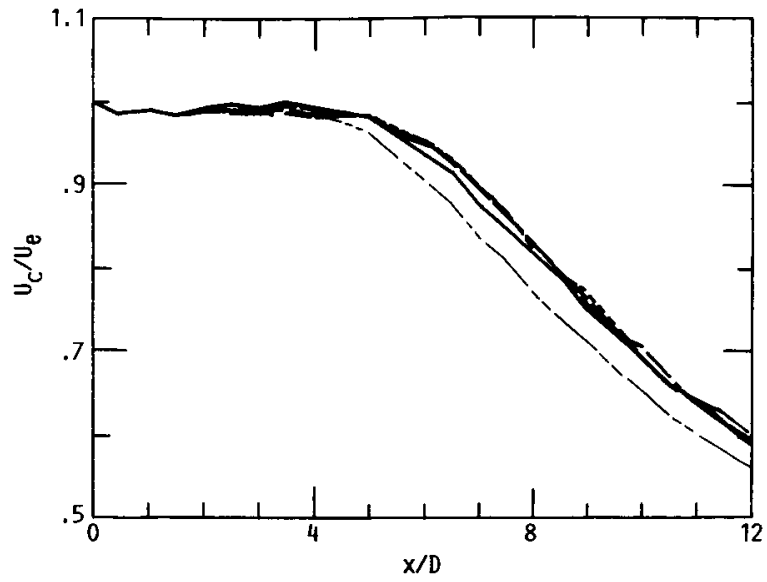

FIGURE $7(A)$. - VARIATION OF THE MEAN VELOCITY ON THE JET AXIS $\left(U_{C}\right)$ AT $M=0.3$ WITHOUT EXCITATION.

$\longrightarrow, 5 x:-0.15 \%$ : $-3 x:---15 \%$

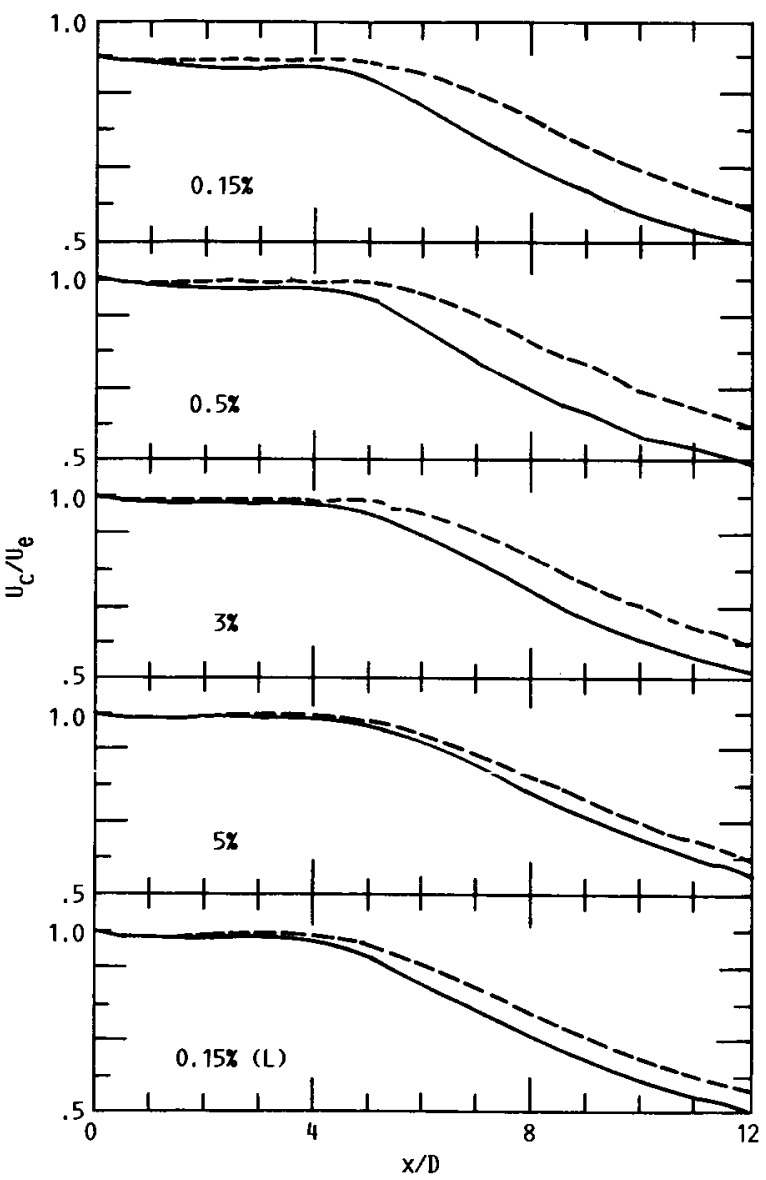

FIGURE $7(B)$. - VARIATION OF $U_{C}$ AT $M=0.3$ FOR THE FIVE CASES AS INDICATED: - - - - NO EXCITATION: EXCITATION AT ST $=0.47(537 \mathrm{~Hz})$

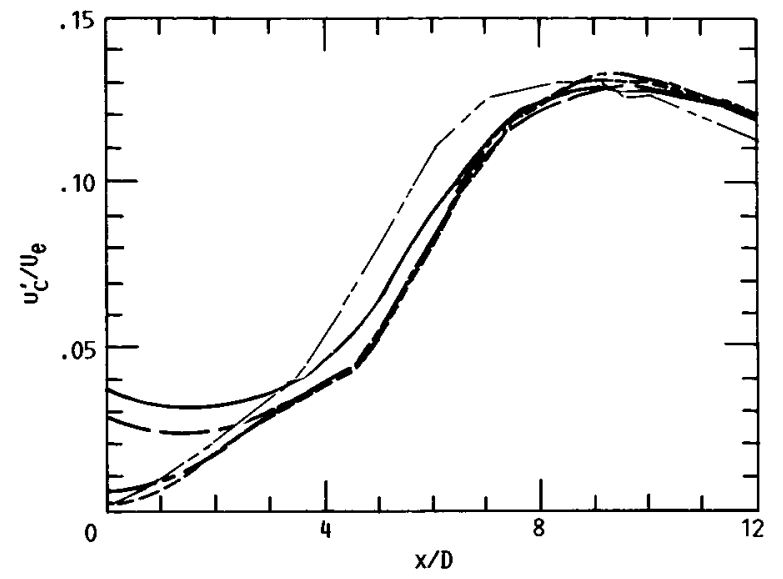

FIGURE 8(A). - VARIATION OF THE TURBULENCE INTENSITY ON THE JET AXIS $\left(U_{c}^{\prime}\right)$ CORRESPONDING TO THE FIVE CASES OF FIGURE $7(\hat{C})$.

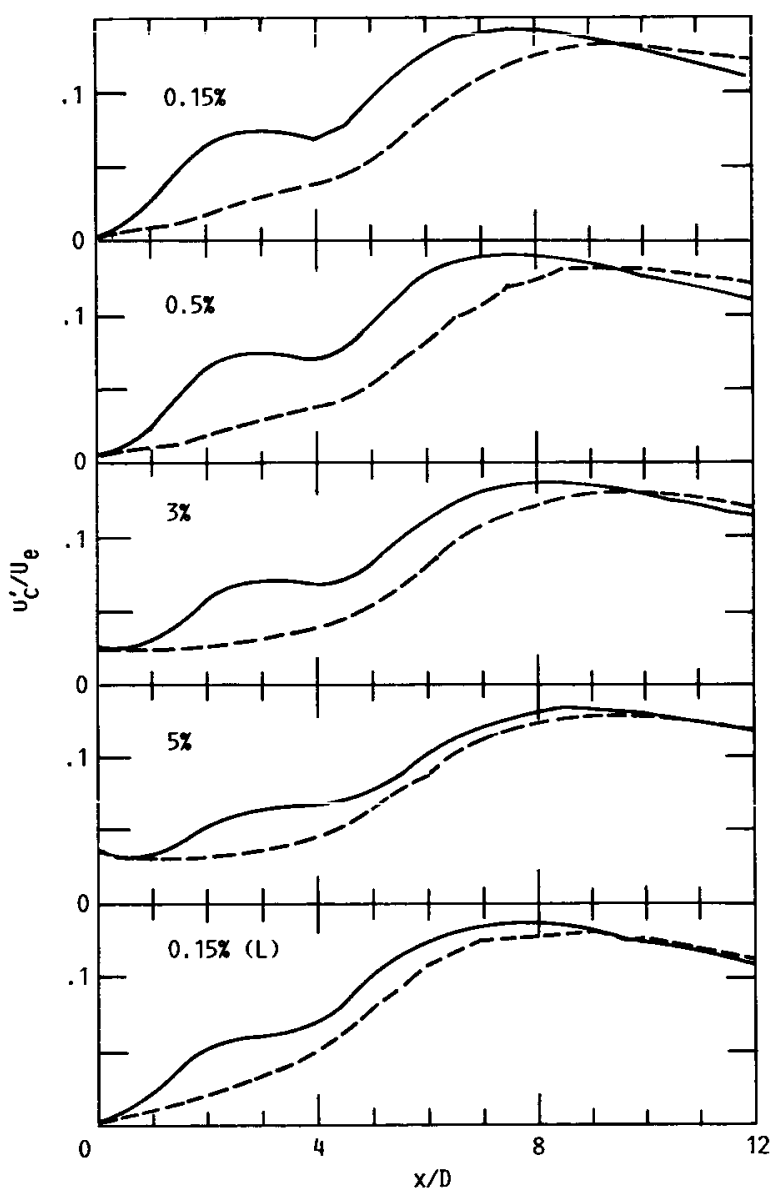

FIGURE 8(B) - U'-VARIATION WITH AND WITHOUT EXCITATION CORRESPONDING TO THE FIVE CASES OF FIGURE 8(A). 


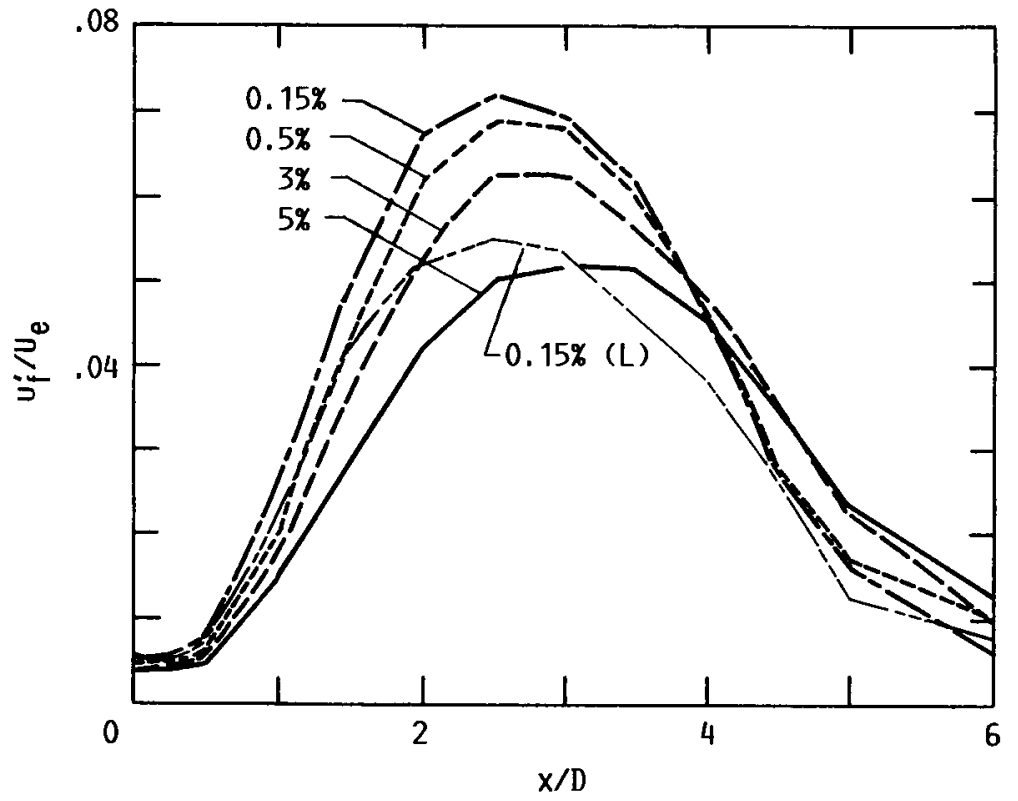

FIGURE 9. - VARIATION OF THE FUNDAMENTAL RMS VELOCITY FLUCTUATION ( $U_{\mathfrak{f}}^{\prime}$ ) ALONG THE JET AXIS CORRESPONDING TO THE EXCITATION CASES OF FIGURES 7(B) AND 8(B). SAME LINE CODES AS IN FIGURE $7(A)$. 


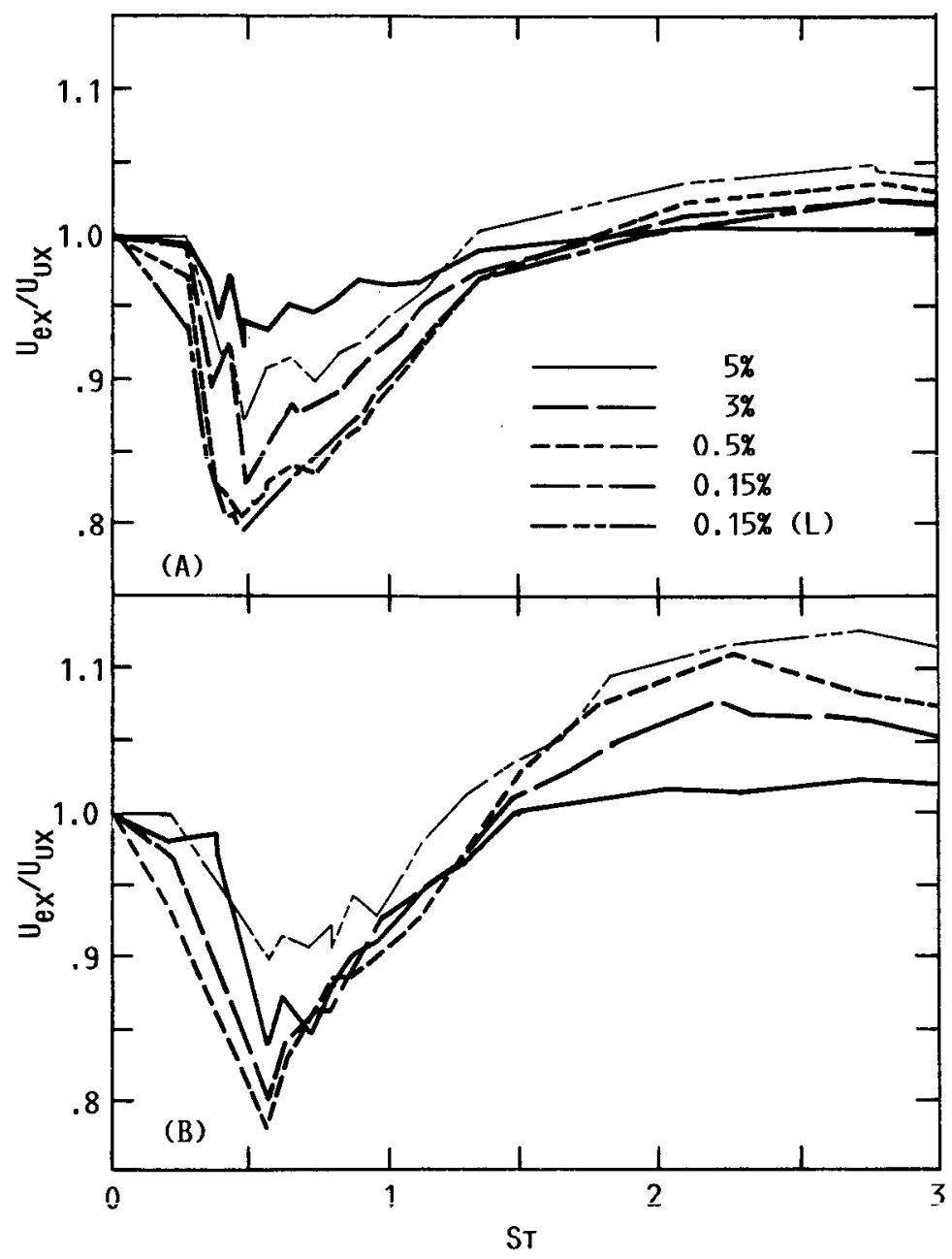

FIGURE 10. - VARIATION OF THE MEAN VELOCITY RATIO WITH AND WITHOUT EXCITATION, MEASURED AT $X / D=9$ ON THE JET AXIS, WITH STROUHAL NUMBER, $S T\left(=\mathrm{f}_{\mathrm{p}} \mathrm{D} / \mathrm{U}_{\mathrm{e}}\right)$. ALL DATA ARE FOR $L_{e}=130 \mathrm{~dB}$. (A) $M=0.3$, (B) $M=0.15$. 


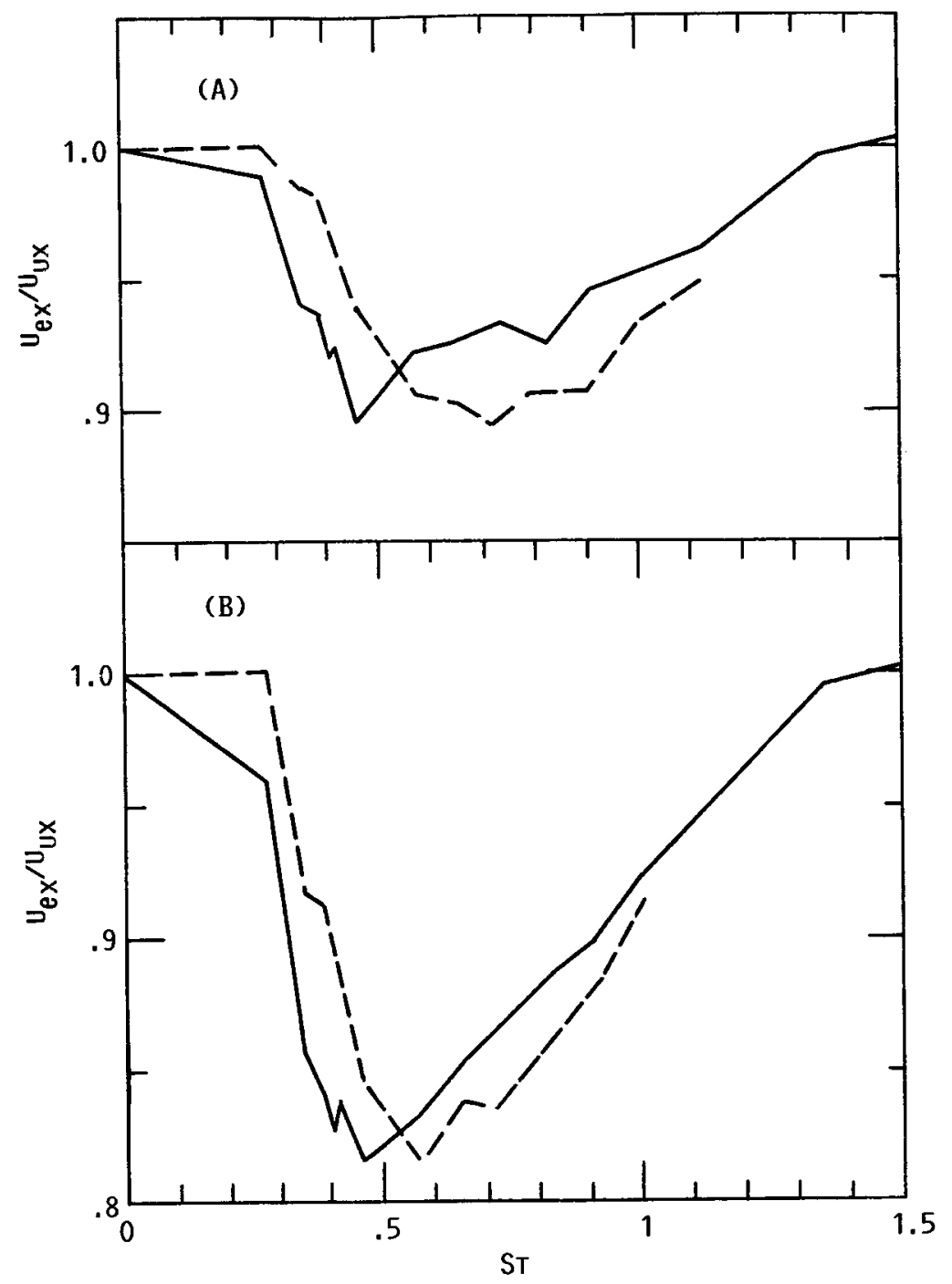

FIGURE 11. - VARIATION OF $U_{e x} / U_{U X}(x / D=9)$ WITH ST AT $M=0.3$. (A) $0.15 \%(L)$, (B) $0.15 \%$; SOLID LINE FOR CONSTANT Le $(130 \mathrm{~dB})$, DASHED LINE FOR CONSTANT $u_{\mathrm{f}}^{\prime} / \mathrm{U}_{\mathrm{e}}$ (0.25\%). 


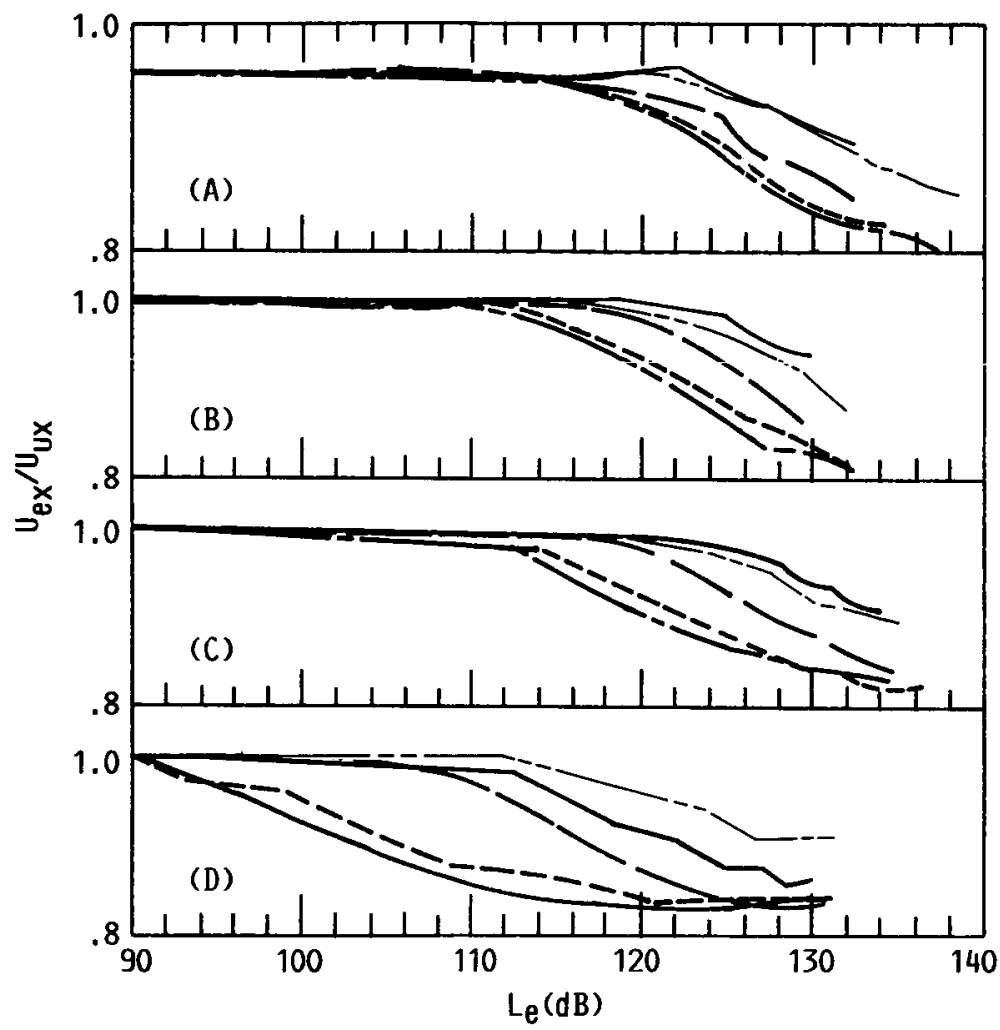

FIGURE 12. - VARIATION OF $U_{e X} / U_{U X}(x / D=9)$ WITH $L_{e}$ FOR: (A) $\mathrm{ST}=0.39$, (B) $\mathrm{ST}=0.47$, (C) $\mathrm{ST}=0.66$, (D) $\mathrm{ST}=0.5 \overline{6}$. (A) - (C) $\overline{F O} \bar{K}$ î̀ $=\overline{0} . \overline{3}$, (D) FOOK $M=0.15$. SAME LINE CODES AS IN FIGURES $7(A)$ AND 10. 


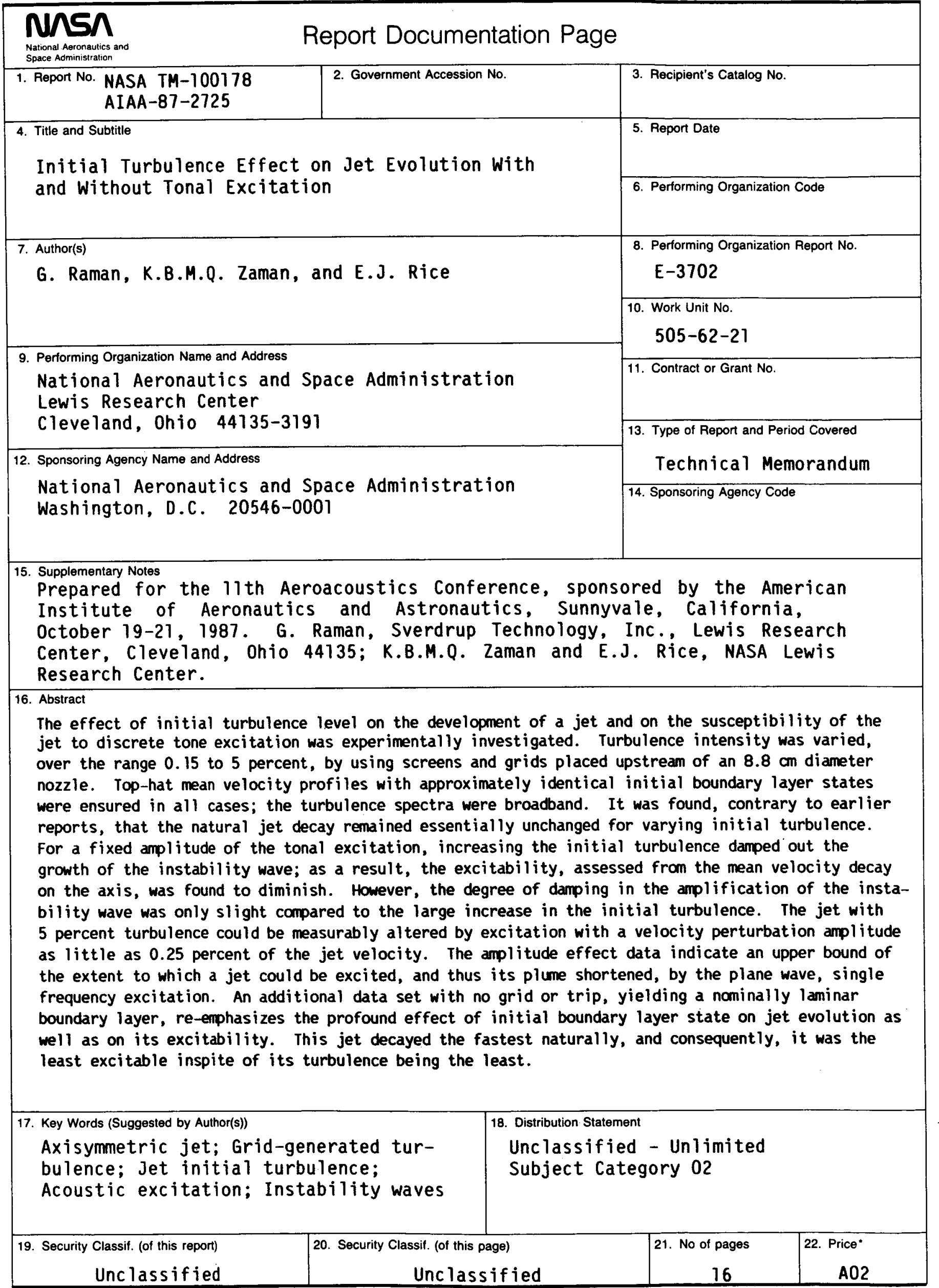

NASA FORM 1626 OCT $86 \quad$ "For sale by the National Technical Information Service, Springfield, Virginia 22161 